\title{
A GESTÃO ORÇAMENTÁRIA E FINANCEIRA DE UMA ESCOLA PÚBLICA
}

\author{
CRUZ, Valmira Maria de Amariz Coelho de \\ BACHTOLE, Ciro \\ SILVA, Frederico Fonseca da
}

\begin{abstract}
RESUMO: O presente trabalho discorre em linhas gerais sobre a gestão orçamentária e financeira de uma escola pública, fazendo uma síntese da parte administrativa e financeira da gestão dessa instituição de ensino e tomando a mesmacomo referência para 0 desenvolvimento do presente estudo. Nessa linha de desenvolvimento, fazum paralelocomo OrçamentoPúblico; a LeiOrçamentária; a Receita Pública, citando conceitos e classificações; as Despesas Públicas, conceituando e citando algumas classificações; e com a Legislação aplicada à Gestão Orçamentária e Financeira, com base naLDB (Lei de Diretrizes e Bases da Educação), citando algumas leis e artigospertinentes ao tema. Enfoca, também, as dificuldades encontradas pela gestão, para administrar os parcos recursos enviados às escolas, discorrendo sobre a situação.
\end{abstract}

Palavras-chave:Gestão Financeira. Gestão Orçamentária. OrçamentoPúblico.

\section{BUDGETANDFINANCIALMANAGEMENTOF APUBLIC SCHOOL}

ABSTRAT:This work talks in general terms about budgetary and financial management, a public school, making a summary of part of the administrative and financial management of this educational institution and taking the same as reference for the development of this study. In this line of development, is a parallel with the public budget; the budget law; the Public Revenue, citing concepts and classifications; public expenditure, conceptualizing and citing some classifications; and the legislation applied to the budgetary and Financial Management, based on the LDB (Lei de Diretrizes e Bases da Educação), citing some laws and articles relevant to the topic. Focuses, on the difficulties encountered by management, to administer the meager resources sent to schools, discussing the situation.

Keywords: Financial management. Budget management. Public budget.

\section{INTRODUÇÃO}

O presente estudo faz um enfoque da dimensão orçamentária que rege as escolas públicas de Pernambuco, em especial uma Escola de Referência em Ensino Médio, situada no município de Camaragibe (PE), pertencente à área metropolitana da capital.

Sua elaboração tem a perspectiva de sintetizar e sistematizar as etapas necessárias para a organização e efetivação das documentações necessárias para o desenvolvimento de uma Gestão Orçamentária e Financeira nas escolas públicas estaduais de Pernambuco. 
A justificativa para se refletir e trabalhar a aquisição, o uso e a aplicação do orçamento financeiro das escolas públicas é de que estamos vivenciando uma escalada ascendente da democratização do ensino público brasileiro, fato que requer transparência nas ações gerenciais. Diante disso, muitos gestores de escolas públicas, obrigam-se, a verdadeiros malabarismos com planilhas, planos e planejamentos (PDE ${ }^{1}, \mathrm{PDDE}^{2}, \mathrm{UEX}^{3}, \mathrm{PNAE}^{4}$,entre outros), embasados, com muito pouco de qualquer fundamentação da legislação educacional vigente no Brasil, mais precisamente da LDB ${ }^{5}$.

Sabe-se que a Constituição Brasileira, através da sua Carta Magna no artigo 205 garante que "a educação é um direito de todos e dever do Estado e da família". E, para que esse direito à educação seja mantido,é preciso garantir que ele esteja inscrito no coração das escolas e cercado de todas as condições (CURY, 2005).

Garantia esta que também está disposta na $\operatorname{LDB}$ e noECA ${ }^{6}$., os quais dispõem sobre a obrigatoriedade gratuita da educação. A garantia da educação também encontra respaldo jurídico no $\mathrm{PNL}^{7}$., aprovado em 2001, nas Constituições Estaduais e nas Leis Orgânicas dos Municípios.

Urge ressaltar, porém, que para que realmente se efetive ao jovem cidadão brasileiro a garantia do direito legítimo à educação básica e fundamental, torna-senecessário a garantia do financiamento dessas etapas do ensino. Fato consumado desde a Constituição de 1934 onde o governo já prevê recursos financeiros (frugais - 10\%) para a educação.

Atualmente, embasados na Constituição Federal de 1988, especificamente, em seu artigo 212, tem-se que serão destinados, anualmente, à educação, capital igual ou superior a $18 \%$ dos recursos da União. De forma semelhante, os Estados, o Distrito Federal e os Municípios devem destinar ao setor educacional nada menos de $25 \%$ da receita dos impostos (DOURADO,

\footnotetext{
${ }^{1}$ PDE - Plano de Desenvolvimento da Escola.

2 PDDE - Programa Dinheiro Direto na Escola. Foicriadoem 1995, pela Resolução FNDE/CD n 12. Disponível no site: http://gestao2010.mec.gov.br/o_que_foi_feito/program_61.php.

${ }^{3}$ UEX - Unidade Executora.

${ }^{4}$ PNAE - Programa Nacional de Alimentação Escolar.

${ }^{5}$ LDB - Lei de Diretrizes e Bases.

${ }^{6}$ ECA - Estatuto da Criança e do Adolescente.

${ }^{7}$ PNL - Plano Nacional de Educação.
} 
2006). Vale salientar que o §5,do artigo 212,da Constituição Federal de 1988 (BRASIL, 1988), reza que a educação terá como fonte adicional de financiamento a contribuição social do salário-educação.

Ainda com relação ao financiamento da educação, Dourado (2006), argumenta que a Emenda Constitucional $n^{\circ} 14$, de setembro de 1996, alterou 0 artigo 211 da C.F. 1988 dando para o $§ 1^{\circ}$ a seguinte redação:

\begin{abstract}
"A União organizará o sistema federal de ensino e o dos territórios, financiará as instituições de ensino públicas federais e exercerá, em matéria educacional, função redistributiva e supletiva, de forma a garantir equalização de oportunidades educacionais e padrão mínimo de qualidade do ensino mediante assistência técnica e financeira aos estados, ao Distrito Federal e aos municípios" (BRASIL, 1988).
\end{abstract}

Estes enunciados deixam claro que tanto o acesso, quanto a gratuidade do ensino brasileiro têm relação direta com o financiamento da educação garantido pela Emenda Constitucional $n^{\circ} 14$.

Hoje, não deveria mais existir pessoas despreparadas e sem o mínimo de conhecimento das leis que fundamentam a educação no Brasil, porém, a realidade nos mostra que ainda há carência na capacitação de gestores escolar quanto às questões orçamentárias e financeiras. É de fundamental importância que não apenas o gestor, mas toda a sociedade entenda ou tenha o mínimo conhecimento dessas leis, pois são elasque regem e norteiam aorganização e a gestão da educação brasileira, tendo em vista que as mesmas regulamentam, não só as políticas públicas, os programas e as ações administrativas governamentais, mas, principalmente, 0 financiamento destinado à educação, garantindo dessa forma o direito do cidadão a uma educação gratuita.

Este trabalho tem, ainda, a expectativa de que os tópicos aqui desenvolvidos abram perspectivas e provoquem novas ideias, ainda que em um cenário de poucos recursos, como é o caso das escolas públicas brasileiras, viabilizando uma gestãoorganizada, fidedigna e transparente, que proporcione também, subsídios para que na prática, o gestor saiba trabalhar no conflito e na tensão, - gerados pela falta ou pelo pouco recurso financeiro para atender as demandas e necessidades da escola -de modo que a mesma possa 
cumprir o seu papel que é o de ofertar, sempre, um ensino de qualidade para o seu público.

É nesse contexto de organização e transparência que se tomou como referencial para esse trabalho a gestão financeira de uma escola pública do Estado de Pernambuco, situada no município de Camaragibe, e se tem a pretensão de que o seu exemplo de gerenciamento possa contribuir para que as demais escolas públicas brasileiras solucionem ou minimizem os conflitos nessa área de atuação.

Portanto, o que se pretende neste trabalho é apresentar, de maneira clara e objetiva, o tema referente às questões do orçamento das escolas públicas contido na LDB e cujo conhecimento é indispensável para que o gestor da escola pública possa elaborar, fidedignamente, a gestão orçamentária e financeira da 'sua escola.

\section{DESENVOLVIMENTO}

\subsection{Orçamento público}

A crise que envolve a educação pública no Brasil, traz implícita vários fatores destacando-se, dentre tantos, o fator recurso público destinado à educação. Subtende-se que o mesmo destina-se a "garantir" as condições necessárias para que na prática se efetive o que rege a $\operatorname{LDB}^{8}$ de 1996 (Lei $n^{\circ}$ 9.394), com relação a uma educação "gratuita”(BRASIL, 1996).

Nesse sentido, é relevante entender o que é orçamento público, bem como, a sua relação existencial com as escolas públicas brasileiras.

No orçamento destacam-se os aspectos político, econômico, técnico e jurídico. $\mathrm{O}$ aspecto político envolve a destinação de recursos em ações sociais e regionais; $O$ aspecto econômico retrata a realidade da economia revelada pelo orçamento; O aspecto técnico está presente nos cálculos realizados para estimativa da receita e fixação da despesa; e,o aspecto jurídico apresenta-se

8 LDB -Lei de Diretrizes e Bases da Educação Nacional, de 1996. Mantém a responsabilidade de o Estado oferecer a educação escolar pública e gratuita. 
na vinculação orçamentária às normas legais que incluem a Constituição Federal e as leis infraconstitucionais (PALUDO, 2015).

O orçamento público é respaldado em lei, e abrange todas as esferas da administração pública, configurando-se como ferramenta primordial para que as ações pertinentes ao desenvolvimento dessas esferas sejam realmente efetivadas.

O orçamento público é planejado pelo Poder Executivo de cada esfera de governo e deve conter todas as receitas e todas as despesas públicas, de modo que estas venham a atender as ações prioritárias de uma região, proporcionando à sociedade o atendimento de suas necessidades básicas ${ }^{9}$.

Para tanto, é necessário que as pessoas diretamente envolvidas na administração do orçamento público, tenham uma real apropriação das necessidades e direcionamento das ações prioritárias da região aondese venha aexecutar as atividades desse orçamento.

O orçamento é, na verdade, o somatório de toda a receita prevista para um período (é um exercício financeiro aonde no caso do $\mathrm{PPA}^{10}$, vai além de um exercício financeiro) e de todas as despesas que poderão ser efetuadas administrativamente.

Como o orçamento público atinge todas as dimensões da administração pública, obviamente ele deve ser um instrumento de gestão dessas esferas e, nesse cenário, dependendo do contexto no qual esses recursos irão ser aplicados, existem várias formas, tanto para elaborar o planejamento, quanto para a utilização dos mesmos, como: Orçamento Tradicional, Orçamento a Base-zero, Orçamento-Programa e Orçamento Participativo.

Para um melhor entendimento segue, em breves linhas, a conceituação de cada um desses tipos de orçamento.

O Orçamento Tradicional, anterior ao Orçamento Programa consistia, segundo Angélico (2009), do relacionamento entre as receitas a serem arrecadadas e as despesas de custeio. Este tipo de orçamento mostrava o que

\footnotetext{
${ }^{9}$ AVILA, A.C. Gestão Orçamentária e Financeira. 2011, p.14-15.

${ }^{10} \mathrm{PPA}$ - Plano Plurianual.
} 
se pretendia gastar ou comprar. Do resultado positivo do total dessa relação dependia o investimento nos serviços públicos.

Já o Orçamento Base Zero, tem como premissa desconsiderar os dados anteriores, leva em consideração, apenas, os dados atuais ${ }^{11}$. Consiste em uma discussão prévia das atividades da empresa, para, em seguida, proceder-se à elaboração do orçamento.

O Orçamento Programa é o elo entre o planejamento e as funções executivas da organização, na visão de Andrade (2012), traduz a política econômico-financeira da administração. Este modelo de orçamento, de acordo com Angélico (2009), destaca as metas e as intenções do Governo, e tem custo definido,

Neste tipo de orçamento os gestores apresentam justificativas para apropriação dos recursos, questionando os gastos e a real necessidade dos mesmos.

O Orçamento Participativo, técnica orçamentária caracterizada pela participação popular na decisão de alocação de alguns recursos, teve como pioneiros os municípios de Porto Alegre (RS) e Santo André (SP), na gestão 1989-1992 (PALUDO, 2015). Sua elaboração evidencia um ato democrático pelo qual a comunidade pode opinar na definição de políticas governamentais.

Nas várias regiões, estados e municípios brasileiros, a criação de seus orçamentos acontece de forma análoga, visto que, existe uma base única na Constituição Federal de 1988 normatizando sua elaboração, em especial no título de orçamentos que abrange os artigos de número 165 a 169 (BRASIL, 1988).

Há normatização orçamentária, também, nas respectivas constituições estaduais e leis orgânicas dos municípios, sempre respeitando a ordem de hierarquia das leis para que sejam cumpridas as exigências legais primeiro da Constituição Federal, depois da constituição estadual e por fim, da lei orgânica

11 Orçamento Base Zero. Dados acessados aos 09 de setembro de 2012, às 12:20h, disponível no site: www.keepandshare.com/.../conceitos-e-tipos-de-orcamentos-pdf-febr. 
municipal, onde a lei de hierarquia menor não pode se sobrepor à lei de hierarquia maior.

Nessa linha de criação, planejamento e divisão do orçamento público, de acordo com o descrito no artigo 165, da Constituição Federal 88 (BRASIL, 1988), aparecem, com suas características e classificações,três leis, que são: o $P A^{12}$ - que contém objetivos, diretrizes e metas da administração pública para um mandato, atualmente, de quatro anos. O Plano Plurianual é elaborado no primeiro ano de mandato e tem duração até o primeiro ano do mandato da próxima gestão; a $\mathrm{LDO}^{13}$ - que deve contemplar os objetivos estabelecidos no PPA e norteia a elaboração dos orçamentos anuais; e a $L \mathrm{~A}^{14}$ - lei que efetiva e executa as diretrizes anuais para os quatro anos de governo,com abrangência de um ano e grau de detalhamento que contempla todas as receitas e despesas públicas previstas para o próximo exercício. Ao final do mandato do governante ele terá elaborado um plano plurianual, quatro LDOs, e, respectivamente, quatro LOAs.

De acordo com o artigo 165, da Constituição Federal de 1988, as leis orçamentárias anuais devem constituir-se de três partes distintas ${ }^{15}$, com vistas a facilitar sua aplicação durante a execução.

Já na concepção de Kohama (1998) o processo orçamentário deve ser direcionado ao bem estar da sociedade e controlar o empenho do dinheiro público, por meio de trabalho técnico que busca aperfeiçoar racionalmente o uso do recurso público para que a população tenha acesso ao maior número de bens e serviços possível.

Para a elaboração do orçamento público é necessária a adoção de regras específicas, denominadas Princípios Orçamentários básicos. Não há consenso entre autores sobre o número desses princípios, porém em outras

\footnotetext{
${ }^{12}$ PPA - Plano Plurianual. Instrumento primordial no planejamento das ações de um governante. Caracteriza-se pelo fato de que o governante, elabora o projeto de lei para vigência nos próximos 4 anos, 3 anos do mandato deste gestor e um do próximo mandato, mas deve atender no primeiro ano de gestão o que foi proposto por seu antecessor (GIACOMONI, 2010).

${ }^{13} \mathrm{LDO}$ - Lei de Diretrizes Orçamentárias.

${ }^{14}$ LOA - Lei do Orçamento Anual.

${ }^{15}$ Lei OrçamentáriaAnual - a LOA é umaúnica lei orçamentáriaanualcompostade 3partes: Orçamento fiscal, orçamento de investimento e orçamento da seguridade social.
} 
bibliografias $^{16}$ poderão ser encontrados um número maior ou menor, pois isso depende das corrente doutrinária adotada pelos diversos autores, destacandose alguns ${ }^{17}$ : Unidade, Totalidade, Universalidade, Anualidade ou Periodicidade, Exclusividade, Especificação ou Discriminação, Não Vinculação ou Não Afetação da Receita, Orçamento Bruto, Equilíbrio, Legalidade, Publicidade, Clareza ou Objetividade e Exatidão (GONTIJO, 2004). Atualmente, de acordo com o Curso de Orçamento Público da Secretaria de Orçamento Federal (SOF, 2015) pode-se acrescentar ainda os princípios:

- Da Descentralização que defende a execução de ações mais próxima dos beneficiários;

- Da Responsabilização, onde os gestores devem assumir a responsabilidade por desenvolver programa para encaminhamento ou solução de problemas;

- Da Simplificação onde o planejamento e orçamento sejam de fácil compreensão; e,

- Da Programação onde haverá o detalhamento de metas e objetivos a serem alcançados por meio de programas de trabalho.

O Ciclo Orçamentário é o período em que ocorrem todas as etapas concernentes aos aspectos físicos e financeiros dos programas do setor público. Compreende:

- aelaboração, com fixação de objetivosconcretos, distribuídosemdiretrizes e metas;

- o estudo e aprovação,feitoporumacomissão do Legislativo, que apósaprovar as propostas, obedecendodatasprevistas, encaminha- as para o Executivo;

- a execução, quese dáquando a propostajáconvertidaem lei é colocadaemprática; e,

\footnotetext{
${ }_{17}^{16}$ Ementário de Classificação das ReceitasOrçamentárias da União-2008.

Disponível no Site da Câmara dos Deputados Federais em: http://www2.camara.leg.br/atividade-

legislativa/orcamentobrasil/cidadao/entenda/cursopo/principios.html.
} 
- a avaliação, que deve ocorrer de maneira dinâmica e em paralelo à fase de execução do orçamento ${ }^{18}$.

\subsection{Entendendo receita e despesa pública}

A receita pública pode ser entendida como o montante total de dinheiro recolhido pelo Tesouro Nacional incorporado ao patrimônio do Estado, que serve para custear as despesas públicas e as necessidades de investimentos públicos ${ }^{19}$.

Segundo Carvalho (2010), a receita pública se constitui em todo recurso obtido pelo Estado para atender às despesas públicas.

$\mathrm{Na}$ verdade, pode-se simplificar o conceito de receita pública como sendo todo o montante financeiro, que entra nos cofres públicos e que vai ser destinado aos serviços públicos e à comunidade.

Na prática, a receita é de fundamental importância para a Administração Pública, por estar diretamente envolvida em todo o processo orçamentário das diversas esferas governamentais, e por disponibilizar recursos financeiros que viabilizam a execução de ações das políticas públicas para atender as necessidades sociais.

Por conseguinte, a receita é um importante instrumento da Administração, e como tal, de acordo com a definição governamental, assume subdivisões específicas.

Nesse contexto, aparecem: aReceita orçamentáriae a Receita extraorçamentária.

A Receita orçamentária éautorizada pelo legislativo e usada como recurso financeiro para o Estado. É incorporada ao patrimônio do Poder Público e está dividida em $\underline{\text { Receita Corrente }}^{20}$ e Receita de Capital $^{21}$.

\footnotetext{
${ }^{18}$ ÁVILA, BÄCHTOLD, VIEIRA. Noções de ContabilidadePública, 2011, p.51-52.

${ }^{19}$ Receita pública. Disponível:http://pt.wikipedia.org/wiki/Receita_p\%C3\%BAblica.

${ }^{20}$ Receitas corrente- É uma categoria econômica da receita orçamentária. Constitui-se das receitas tributária, patrimonial, transferências correntes e receitas diversas (ANGÉLICO, 2009).

21 Receita de capital - Destinam-se à cobertura de despesas de capital a título de investimentos, com intitulação legal, cria acréscimo ao patrimônio público(ANGÉLICO, 2009). Correspondem às alienações de bens, às amortizações de empréstimos concedidos, e às transferências de capital (ANDRADE, 2012).
} 


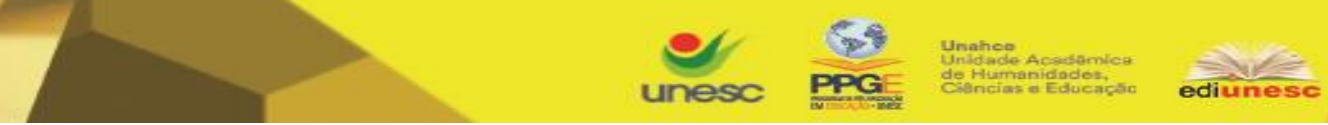

A Receita extra orçamentáriaé temporária e não entra no patrimônio do

Poder Público, é um recurso que é arrecadado pela gestão, mas pertence a terceiros e deverá ser repassada ou devolvida para o próprio contribuinte, portantonão sendonecessário colocá-la no orçamento público. É importante frisar que, devido as operações realizadas entre entidades da Administração Pública, integrantes do orçamento fiscal e da seguridade social de uma mesma esfera do governo e demais órgãos, um novo grupo vem compor a natureza da receita, a Receita intra orçamentária (PALUDO, 2015; AVILA, 2011).

Todas as divisões, subdivisões e classificações da receita pública têm suas atividades de elaboração da proposta orçamentáriaexecutadas através de estágios, o que facilita o conhecimento e a gestão dos ingressos de recursos. Entretanto, as literaturas (ANDRADE, 2002; ANGÉLICO, 2009), divergem em relação ao número de estágios da receita, porém, segundo Ávila, Bächtold e Vieira (2011), a receita apresenta os seguintes estágios: Previsão- estima 0 valor da arrecadação; Lançamento- relação individual do contribuinte discriminando o valor e o vencimento do imposto de cada um; Arrecadaçãose dá quando o contribuinte liquida suas obrigações para com o Estado; e, Recolhimento- acontece quando os recursos financeiros arrecadados são entregues ao Tesouro público.

As despesas públicas, segundo Carvalho (2010), são todos os dispêndios para funcionamento e manutenção dos serviços públicos prestados à sociedade. Outra concepção de Despesa pública é:

"[...] todo o pagamento efetuado, a qualquer título, pelos agentes pagadores para saldar gastos fixados na lei do Orçamento ou em lei especial e destinado à execuçãodos serviços públicos, entre eles custeios e investimento, além dos aumentos patrimoniais, pagamento de dividas, devolução de importâncias recebidas a títulos de caução, depósitos e consignações" (ANDRADE,2002, p.75).

A despesa pública é, portanto, a soma de recursos provenientes da receita pública, cuja aplicação, respaldada por lei, é destinada a atender as necessidades da administração. Divide-se em dois grupos, que são: Despesa Orçamentária e Despesa Extra orçamentária, ambas consideradas de acordo com a sua participação no orçamento. 
As despesas orçamentárias fazem parte do orçamento público, constituem a contribuição do governo em forma bruta do capital.

Segundo Angélico (2009), a despesa orçamentária depende de autorização do legislativo e de crédito orçamentário correspondente e, de acordo com o artigo 12, da Lei 4.320/64, classificam-se nas categorias econômicas de: Despesas Correntes e de Capital(CARVALHO, 2010; PALUDO, 2015; GIACOMONI, 2010).

As Despesas Correntes, de acordo com Ávila, Bächtold, Vieira (2011), referem-se aos gastos operacionais em que a administração pública faz uso dos recursos para manter em funcionamento a máquina administrativa do Estado.

Já as Despesas de Capital, no entender de Andrade (2012), contribuem para formar um bem de capital ou para acrescentar valor a um bem já existente, isto feito através do planejamento, da aquisição de instalações e de material permanente, da amortização de dívidas e de concessões de empréstimos.

As Despesas de Capital representam a destinação de recursos que irão aumentar o patrimônio público (BÄCHTOLD, 2009).A subdivisão da despesa pública está em proporção direta à sua participação no orçamento.

A Figura 1representa simplificadamente, as divisões, as subdivisões e as especificações das referidas despesas.

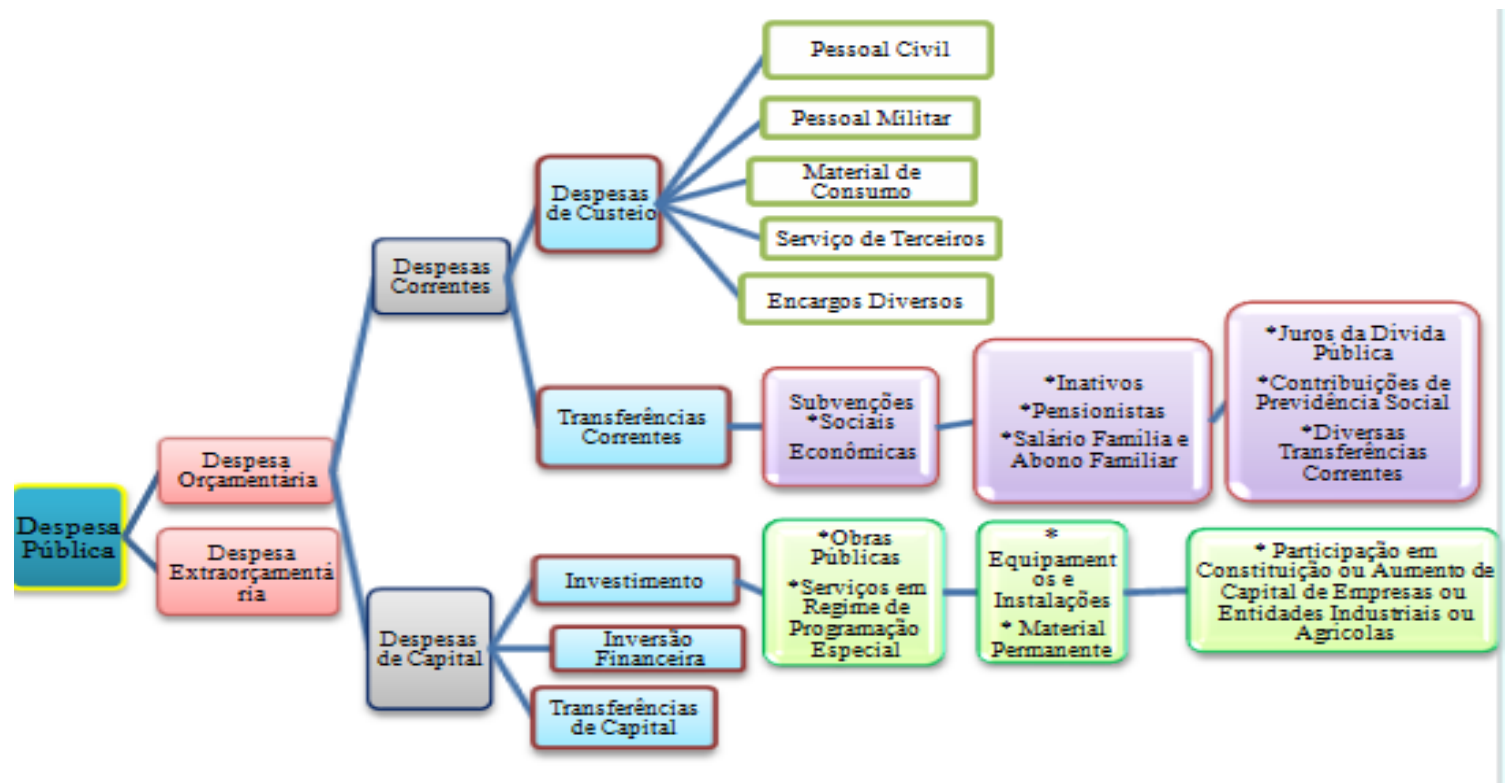

Criar Educação, Criciúma, v. 6, nº1, janeiro/junho 2017.- PPGE - UNESC 
Figura 1. Divisão, subdivisão e especificações das DespesasOrçamentárias.

Fonte: Dados obtidosno Manual Técnico de Orçamento (BRASIL, 2016).

Para facilitar o controle, a aplicação e o endereçamento das despesas públicas, estas, após publicação da lei orçamentária, obedecerão ao estabelecido na programação financeira dos gastos da instituição, da qual constam as seguintes etapas (Figura 2):

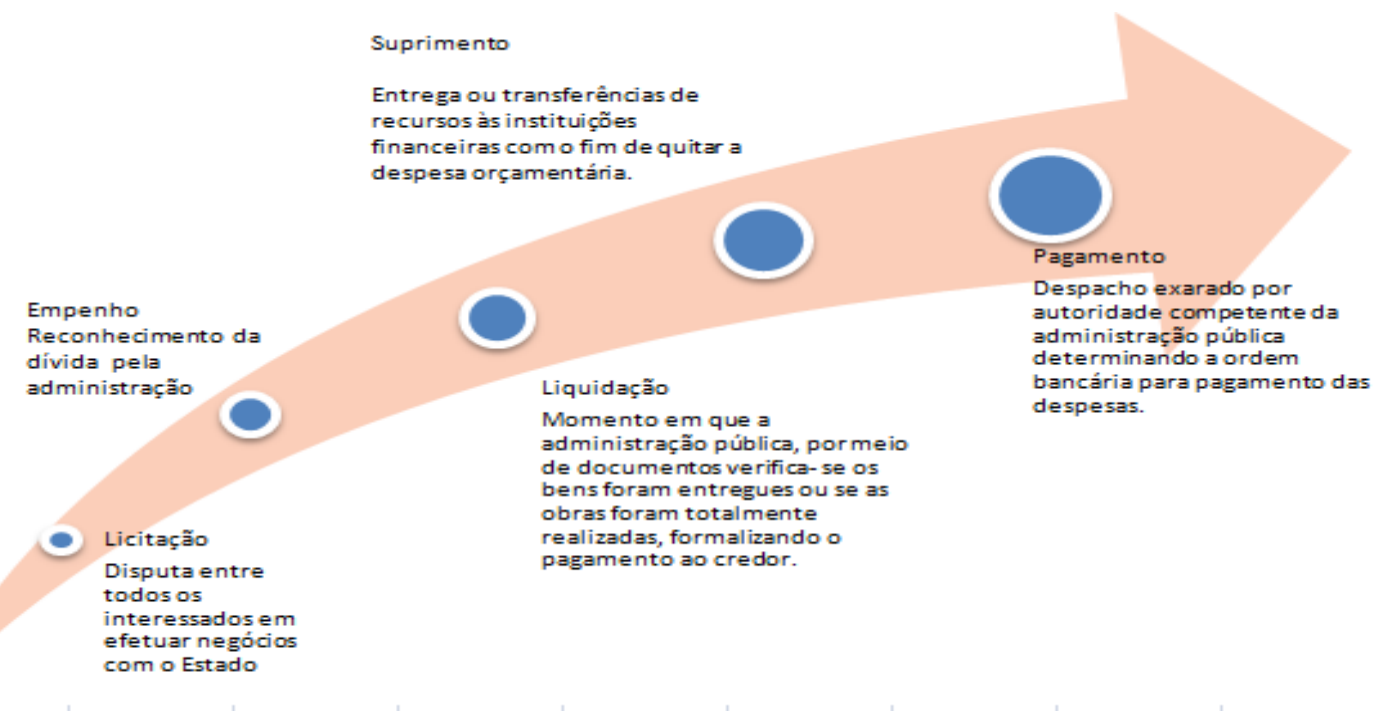

Figura 2. Etapas das despesaspúblicas.

Fonte: Dados relativos a Escola de Referência em Ensino Médio Prof. Carlos Frederico do Rêgo Maciel (Camaragibe - PE).

\subsection{0 recurso público como fonte de receita destinada às despesas para a educação pública e a legislação vigente.}

Para compreender o discurso oficial do orçamento público e as práticas relacionadas ao destino das receitas para as despesas com a educação pública, é necessário compreender que existe uma defasagem, bastante 
acentuada, entre este "discurso" e a prática, ou seja, a sua verdadeira efetivação quanto ao direcionamento das receitas públicas para a melhoria do ensino público e para a garantia do acesso e permanência de milhões de brasileiros a esse ensino.

Na prática, o que se percebe é que esses discursos tornam-se "vazios" quando se constata que ainda existe um número muito grande de analfabetos no país, que milhões de brasileiros estão fora da sala de aula, que existe um déficit no paísde mão de obra qualificada, o que já repercute negativamente na economia e no capital brasileiro, e que a educaçãodo Brasil ocupa um dos piores lugares no contexto da educação mundial.

Segundo dados da $\mathrm{OCDE}^{22}$, a educação tem sido prioridade nas despesas públicas do Brasil nos últimos oito anos. Nesse período, as despesas com educação passaram de $10,5 \%$ para $17,4 \%$ do total do orçamento estatal ${ }^{23}$. O reflexo dessa ação está na queda do índice de analfabetismo no país. Segundo a ONU ${ }^{24}$, em 1970, a taxa de analfabetismo era da ordem de 31,6\%; em 1980, estava em 24\%; em 1990, foi de 18\%; em 2000, reduziu para 13,1\%;e, em 2010 , caiu para $9,6 \%$.

Diante de tais considerações e da evidência de tantas fissuras entre 0 discurso oficial e a fidedignidade no direcionamento dos recursos para a educação, fica evidente que discorrer sobre esse tema envolve polêmicas e corre-se o risco de se contaminar com o subjetivismo ideológico do capitalismo, maquiando com positividade o caos em se encontra a educação no Brasil.

Entretanto, essa abordagem será direta e objetiva, limitando-se ao universo que aparece no palco externo do "discurso".

Nesse cenário, o direito de todos à educação é assegurado pela Constituição Brasileira. Direito este, que traz implícito a presunção de uma educação pública no sentido mais amplo de igualdade de direitos, de acesso,

\footnotetext{
${ }^{22}$ OCDE - Organização para a Cooperação e o Desenvolvimento Econômico.

${ }^{23}$ Informação disponível em: http://www.redebrasilatual.com.br/temas/educacao/2011/09/brasiltem-maior-aumento-de-investimento-em-educacao-entre-30-paises. Acessoaos 16 de setembro de 2012.

${ }^{24}$ Analfabetismo no Brasilsupera a média da América latina. Disponível no site acessado aos 19/07/12 http://www.clicrbs.com.br/especial/rs/portal-social/19,0,3168278,Analfabetismo-noBrasil-supera-media-da-America-Latina-aponta-ONU.html
} 
de permanência e de conclusão dos estudos para todos os cidadãos do país. Supõe-se, portanto, que é na escola pública onde se "efetiva" a educação. Entretanto, para que tal aconteça, esta precisa de recursos financeiros para garantir o mínimo de seu funcionamento.

Nesse contexto, os recursos financeiros para a educação e a sua distribuição estão previstos pela Constituição Federal Brasileira e pela LDB, que ditam:

"A União aplicará anualmente, nunca menos de dezoito, e os Estados, o Distrito Federal e os Municípios vinte e cinco por cento, no mínimo, da receita resultante de impostos, compreendida a proveniente de transferências na manutenção e desenvolvimento do ensino".(CONSTITUIÇÃO FEDERAL, artigo 212 e LDB Art.69) ${ }^{25}$.

Portanto, conforme os ditames da Constituição Federal Brasileira, a União deve aplicar 18\% para a educação e os Estados, Distrito Federal e Municípios $25 \%{ }^{26}$. O artigo 68 , da LDB $n^{\circ} 9.394 / 96$, especifica as fontes de recursos para educação.

Serão recursos públicos destinados à educação os originários de 27 :

I -receitas de impostos próprios da União, dos Estados, do Distrito Federal e dos Municípios;

II -receita de transferência constitucional e outras transferências;

III - receita do salário educação e de outras contribuições sociais;

IV -receitas de incentivos fiscais; e,

V -outros recursos previstos em lei.

É mister frisar, entretanto, que adescentralização tributária,política e financeira, só começou a acontecer após a democratização do Brasil, a partir da Constituição Federal de 1988. Por consequência, permitiu a "democratização" no interior das escolas com eleição direta para gestores e a criação do Conselho Escolar. A este, cabe a responsabilidade de gerir, junto ao gestor, a aplicação e controle dos recursos financeiros que chegam à escola através desse processo de descentralização financeira do Estado.

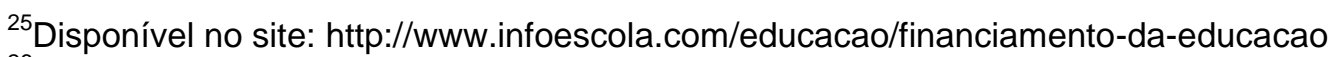

${ }^{26}$ Disponível no site:http://www.jusbrasil.com.br/legislacao/109224/lei-de-diretrizes-e-bases-lei9394-96

27 Disponível no site:http://www.artigonal.com/educacao-artigos/financiamento-da-educacaometas-e-objetivos-2928114.html.
} 
Nesse processo de descentralização do financiamento da educação no Brasil, no ano de 1996, sob a égide da Lei no 9.424/96(BRASIL, 1996), foi criada a Emenda Constitucional $n^{\circ} 14 / 96$ que regulamenta o FUNDEF ${ }^{28}$, que consiste como um fundo de natureza contábil sem órgão gestor ou personalidade jurídica, cuja efetivação se dá através de contas bancárias dos Estados, Distrito Federal e Municípios (artigo $1^{\circ}$ ).

A característica desse fundo é a sua redistribuição com base no $n^{\circ}$ de matrículas no ensino fundamental regular das respectivas redes de ensino. Pelo fato do FUNDEF apresentar um caráter de financiamento limitado apenas ao ensino fundamental, sugiram várias discussões para que houvesse uma maior abrangência do financiamento para a educação. Assim, em junho de 2005, o Ministério da Educação encaminhou ao Congresso Nacional a Proposta de Emenda Constitucional para a criação do FUNDEB $^{29} \mathrm{em}$ substituição ao FUNDEF, com vistas a garantir o financiamento da educação básica em todas as suas etapas e modalidades.

Nesse contexto, e com o objetivo de oferecer uma escola com um ensino universal e de qualidade, bem como o de equalizar as diferenças sociais, várias ações governamentais foram implantadas, surgindo, assim, o PDDE, cuja função é a de respaldar a gestão escolar oferecendo subsídios para aquisição de recursos didáticos pedagógicos, equipamentos e para suprir os reparos e a conservação do prédio escolar. O PDDE foi institucionalizado pela medida provisória $n^{\circ} 1.784 / 98$ (BRASIL, 1998), e sua última reediçãorecebeu o $n^{\circ} 2.178-36$, de 24/08/2001 ${ }^{30}$.

O repasse desses recursos às escolas se dá com a colocação do montante dos recursos enviado em uma conta específica da Unidade

28 FUNDEF - Fundo de Manutenção e Desenvolvimento do Ensino Fundamental e de Valorização do Magistério.

29 FUNDEB - Fundo de Manutenção e Desenvolvimento da EducaçãoBásica e de Valorização dos Profissionais da Educação.

${ }^{30}$ O PDDE foiregulamentado pela Resolução $n^{\circ}$ 6, de 28 de março de 2006 e $n^{\circ} 27$, de 14 de julho de 2006, ambas do Conselhodeliberativo do FNDE. (CORONEL, 2007, p. 12). Informação disponível site:http://www.escoladegoverno.pr.gov.br/arquivos/File/artigos/administracao_orcamentaria _e_financeira/os_mecanismos_operacionais.pdf. 
Executora (UEX), feito através do: PDDE- repasse anual realizado pelo $\mathrm{FNDE}^{31}$ para as contas das unidades escolares, cujos recursos deverão ser utilizados de acordo com as decisões dos órgãos colegiados da escola; $\operatorname{PNAE}^{32}$ e Suprimentos Institucionais - recurso direcionado à escola em quatro parcelas destinadas aos bens de consumo e serviços.

$\mathrm{Na}$ realidade os recursos públicos destinados à educação sofrem 0 "efeito funil". O pouco do recurso que chega às escolas, além de destinados a suprir as necessidades das mesmas - que não são poucas - ainda sofre o afunilamento ocasionado pelos altos índices da carga tributária brasileira, ocasionado por leis mal elaboradas para esse fim.

Nesse sentido, Delphino (2010) afirma que:

\begin{abstract}
"A legislação brasileira carece de leis precisas em relação ao financiamento da educação profissional e dificulta bastante a entrada de recursos oriundos de empresas privadas para atualização e manutenção de pesquisa tecnológica e auxílio para introdução nos laboratórios de equipamentos com tecnologia atualizada".
\end{abstract}

Ainda, segundo a autora, a criação dos Institutos Federais não tem, até o momento,

"um orçamento com dotação específica determinada por legislação, mas depende ainda das condições anuais do orçamento da União, correndo o risco de ficar ao desamparo com uma mudança drástica de políticas ou governo".

Dessa forma, constata-se que gerir a área financeira de uma instituição escolar é um grande desafio para o gestor(a), pois requer uma gestão que trabalhe no coletivo, priorizando as reais necessidades da escola, ou seja, uma gestão verdadeiramente democrática.

\title{
2.4 Gestão financeira e orçamentária de uma escola pública estadual de referência em ensino médio tomada como modelo neste trabalho.
}

\footnotetext{
${ }^{31}$ FNDE - Fundo Nacional de Desenvolvimento da Educação.

${ }^{32}$ PNAE - Programa Nacional de Alimentação Escolar.
} 
A escola tomada como referência nesse trabalho situia-se em Camaragibe (PE). É uma escola de referência em ensino médio e funciona em regime integral. É de médio porte e tem um corpo discente formado por 398 alunos e um corpo docente formado por 17 professores. Desenvolve uma gestão democrática, cuja missão se traduz na busca pela excelência na qualidade do ensino.

Com relação à gestão financeira da escola, esta é realizada pela equipe gestora em conjunto com o Conselho Escolar. A gestora controla as despesas operacionais diariamente, apresentando os resultados aos demais membros da Equipe gestora, e ao Conselho Escolar em reuniões periódicas, nas quais se tomam as decisões que se achar cabíveis.

As necessidades dos recursos financeiros e humanos para atender as estratégias e planos da unidade de ensino, são levantadas na reunião anual de Planejamento estratégico, em conjunto com o Conselho Escolar.

Com vistas a minimizar os eventuais problemas que, obviamente, surgem em qualquer área, a escola busca recursos financeiros alternativos com parceiros e instituições privadas.

$\mathrm{Na}$ elaboração dos planos de ação do Planejamento estratégico e do Plano de aplicação são levantados os recursos necessários referentes à pessoal, treinamento, tecnologia, manutenção, reforma da escola e equipamentos. Estes são traduzidos em recursos financeiros que irão compor o orçamento de investimento. Desta forma, fica assegurado o suporte da gestão financeira às estratégias e planos de ação.

No Quadro 1 é demonstrativa dos recursos recebidos pela instituição de ensino enfocada neste trabalho, no período de 2007 a 2011.

Criar Educação, Criciúma, v. 6, nº1, janeiro/junho 2017.- PPGE - UNESC 
CRIAR EDUCAĈ̃AOO

\begin{tabular}{|c|c|c|c|c|c|}
\hline $\begin{array}{c}\text { AN } \\
0\end{array}$ & ORIGEM & $\begin{array}{l}\text { VALO } \\
\text { R (R\$) }\end{array}$ & DESTINO & $\begin{array}{c}\text { PERÍODO } \\
\text { DE } \\
\text { RECEBIME } \\
\text { NTO }\end{array}$ & OBS. \\
\hline \multirow{3}{*}{$\begin{array}{l}200 \\
7\end{array}$} & $P D D E$ & $\begin{array}{c}8.996 \\
20\end{array}$ & $\begin{array}{c}\text { CAPITAL:1. } \\
799,24 \\
\text { CUSTEIO: } \\
7.196,96\end{array}$ & & PARCELA ÚNICA \\
\hline & PNAE & $\begin{array}{c}15.35 \\
3,36\end{array}$ & MERENDA & & 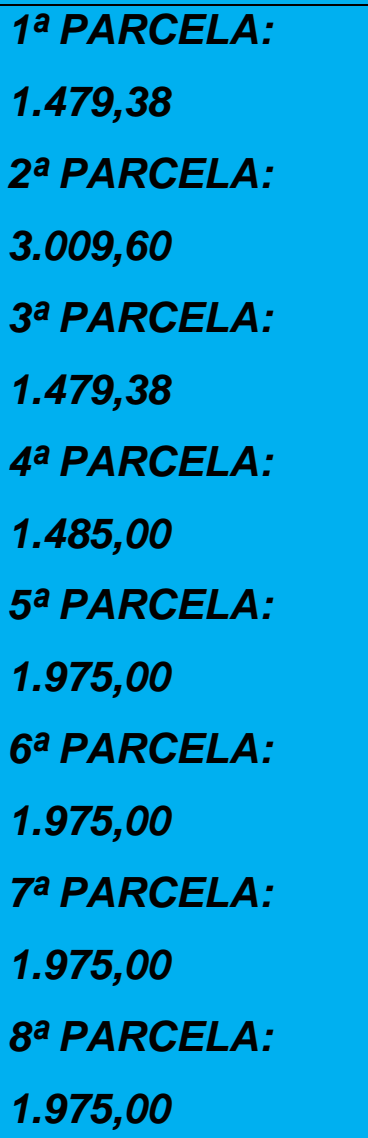 \\
\hline & $\begin{array}{c}\text { SUPRIME } \\
\text { NTO } \\
\text { INSTITUCI } \\
\text { ONAL }\end{array}$ & $\begin{array}{c}32.00 \\
0,00\end{array}$ & $\begin{array}{c}\text { SERVIÇOS: } \\
50 \% \\
\text { CUSTEIO: } \\
50 \%\end{array}$ & & $\begin{array}{l}4 \text { PARCELAS DE } \\
8.000,00\end{array}$ \\
\hline TOT & & & 56.349, & & \\
\hline $\begin{array}{l}200 \\
8\end{array}$ & $P D D E$ & $\begin{array}{c}9.517 \\
40\end{array}$ & $\begin{array}{l}\text { CAPITAL: } \\
\text { 1.903,48 } \\
\text { CUSTEIO: }\end{array}$ & & PARCELA ÚNICA \\
\hline
\end{tabular}

Criar Educação, Criciúma, v. 6, ํำ, janeiro/junho 2017.- PPGE - UNESC 
CRIAR EDUCAĈ̃ÃO

\begin{tabular}{|c|c|c|c|c|}
\hline & & & $7.613,92$ & \\
\hline & PNAE & $\begin{array}{c}15.80 \\
0,00\end{array}$ & MERENDA & $\begin{array}{l}8 \text { PARCELAS DE } \\
1.975,00\end{array}$ \\
\hline & $\begin{array}{c}\text { SUPRIME } \\
\text { NTO } \\
\text { INSTITUCI } \\
\text { ONAL }\end{array}$ & $\begin{array}{l}40.00 \\
0,00\end{array}$ & $\begin{array}{c}\text { SERVIÇOS: } \\
50 \% \\
\text { CUSTEIO: } \\
50 \%\end{array}$ & $\begin{array}{l}5 \text { PARCELAS DE } \\
8.000,00\end{array}$ \\
\hline TOT & & & 65.317, & \\
\hline & PDDE & $\begin{array}{l}16.14 \\
5,00\end{array}$ & $\begin{array}{c}\text { CAPITAL:12 } \\
\text { 916,00 } \\
\text { CUSTEIO: } \\
3.229,00\end{array}$ & PARCELA ÚNICA \\
\hline & $P D E$ & $\begin{array}{l}43.00 \\
0,00\end{array}$ & $\begin{array}{c}\text { CAPITAL:30 } \\
.100,00 \\
\text { CUSTEIO: } \\
2.900,00\end{array}$ & PARCELA ÚNICA \\
\hline $\begin{array}{l}200 \\
9\end{array}$ & PNAE & $\begin{array}{c}12.80 \\
4,00\end{array}$ & MERENDA & $\begin{array}{l}\text { 1ª PARCELA: } \\
\text { 1854,60 } \\
2^{a} \\
\text { PARCELA:1.854,6 } \\
0 \\
3^{a} \text { PARCELA: } \\
\text { 1742,40 } \\
4^{a} \text { PARCELA: } \\
\text { 1742,40 } \\
\text { 5ªARCELA: } \\
\text { 950,00 } \\
\text { 6ª PARCELA: } \\
\text { 950,40 } \\
\text { 7ª PARCELA: } \\
\text { 1.854,60 } \\
\text { 8ª PARCELA: } \\
\text { 1.854,60 }\end{array}$ \\
\hline
\end{tabular}

Criar Educação, Criciúma, v. 6, nº1, janeiro/junho 2017.- PPGE - UNESC 
CRIAR EDUCACCÃO

\begin{tabular}{|c|c|c|c|c|c|}
\hline & $\begin{array}{c}\text { SUPRIME } \\
\text { NTO } \\
\text { INSTITUCI } \\
\text { ONAL }\end{array}$ & $\begin{array}{l}40.00 \\
0,00\end{array}$ & $\begin{array}{c}\text { SERVIÇOS: } \\
50 \% \\
\text { CUSTEIO: } \\
50 \%\end{array}$ & & $\begin{array}{l}5 \text { PARCELAS DE } \\
8.000,00\end{array}$ \\
\hline TOTA & & & 111.949 & & \\
\hline \multirow{5}{*}{$\begin{array}{l}201 \\
0\end{array}$} & PDDE & $\begin{array}{c}17.84 \\
2,00\end{array}$ & $\begin{array}{c}\text { CAPITAL:12 } \\
.489,40 \\
\text { CUSTEIO: } \\
5.352,60\end{array}$ & & PARCELA ÚNICA \\
\hline & $P D E$ & $\begin{array}{c}21.50 \\
0,00\end{array}$ & $\begin{array}{c}\text { CAPITAL:15 } \\
.050,00 \\
\text { CUSTEIO: } \\
6.450,00\end{array}$ & & $\begin{array}{l}\text { PARCELACOMPL } \\
\text { EMENTAR }\end{array}$ \\
\hline & PNAE & $\begin{array}{r}21.77 \\
2,80\end{array}$ & MERENDA & & $\begin{array}{l}8 \text { PARCELAS DE } \\
2.721,60\end{array}$ \\
\hline & $\begin{array}{c}\text { MAIS } \\
\text { EDUCAÇÃ } \\
0\end{array}$ & $\begin{array}{r}25.20 \\
7,50\end{array}$ & $\begin{array}{c}\text { CAPITAL } \\
23.807,50 \\
\text { CUSTEIO } \\
1.400,00\end{array}$ & & PARCELA ÚNICA \\
\hline & $\begin{array}{c}\text { SUPRIME } \\
\text { NTO } \\
\text { INSTITUCI } \\
\text { ONAL }\end{array}$ & $\begin{array}{c}40.00 \\
0,00\end{array}$ & $\begin{array}{c}\text { SERVIÇOS: } \\
50 \% \\
\text { CUSTEIO: } \\
50 \%\end{array}$ & & $\begin{array}{l}5 \text { PARCELAS DE } \\
8.000,00\end{array}$ \\
\hline $\begin{array}{l}\text { TOT } \\
\text { AL }\end{array}$ & & & $126.322,30$ & & \\
\hline \multirow[t]{2}{*}{$\begin{array}{c}201 \\
1\end{array}$} & PDDE & $\begin{array}{l}13.27 \\
4,60\end{array}$ & $\begin{array}{c}\text { CAPITAL: } \\
9.292,22 \\
\text { CUSTEIO: } \\
3.982,38\end{array}$ & JULHO & PARCELA ÚNICA \\
\hline & PNAE & $\begin{array}{c}20.00 \\
0,00\end{array}$ & MERENDA & $\begin{array}{c}1^{\underline{a}} \\
\text { PARCELA: }\end{array}$ & $\begin{array}{l}\text { PARCELAS DE } 5 \\
000,00\end{array}$ \\
\hline
\end{tabular}

Criar Educação, Criciúma, v. 6, ํำ, janeiro/junho 2017.- PPGE - UNESC 
fundamentais de uma unidade de ensino que prioriza, tanto o bem estar dos que nela convivem, quanto um ensino de qualidade.

Fatores como a imposição no direcionamento dos recursos e a variação negativa, no valor do recurso financeiro enviado, prejudica a organização da escola como um todo. Essa assertiva fica evidenciada, pela variação do montante dos recursos destinados, anualmente, à alimentação dos educandos.

Claro está que a máquina governamental não cumpre o que diz a Constituição Federal de 1988 em relação à educação e ao bem estar dos seus cidadãos.

Haja vista que :

- No ano de 2007, o recurso do PNAE era da ordem de $\mathrm{R} \$$ 15.353,36;

- Em 2008, era da ordem de $\mathrm{R} \$ 15.800,00$, ou seja, teve acrescido, apenas, 2,9\%;

- Em 2009, houve uma drástica redução de 19\%, resultando no envio de, apenas, $\mathrm{R} \$ 12.804,00$.

- Já em 2010, comemorou-se um percentual positivo de 58\% no recurso do PNAE, totalizando $\mathrm{R} \$ 21.772,80$.

- Porém, em 2011, o valor enviado foi, para menos, da ordem de $R \$ 20.000,00$.

Percebe-se que, na prática, inexiste o real compromisso com a educação.

Outro ponto negativo a ser apontado está no atraso e na irregularidade com que se processa o repasse desses recursos, muito embora reze a Lei de Diretrizes Básicas, em seu $\S 6^{\circ}$, artigo 212, que "o atraso da liberação sujeitará os recursos à correção monetária e à responsabilização civil e criminal das autoridades competentes" (ANDRADE, 2012). Os atrasos existem, fator que em muito prejudica o andamento das atividades da escola.

A aplicação de todos os recursos obtidos se dá por meio das seguintes etapas:

1. Recebe-se os recursos depositados na conta da escola; 
2. Reúne-se o Conselho Escolar para definir, conjuntamente, as prioridades para a aplicação dos recursos;

3. Definidas as prioridades, faz-se a pesquisa de preços;

4. Faz-se a análise da pesquisa de preços e se dá a ordem de compra;

5. Faz-se a prestação de contas, encaminhando-as a SEE ${ }^{33}$ (Secretaria de Educação do Estado);

6. Realiza-se reunião com a comunidade escolar para o informe do que foi feito com os recursos recebidos; e,

7. Todas as etapas concernentes à gestão financeira desta Unidade de Ensino são registradas em Atas, devidamente assinadas pela gestora e demais componentes do Conselho Escolar.

Diante do exposto, fica evidente que para se gerir financeiramente uma escola pública é necessário que haja, organização, planejamento, criatividade, iniciativa, empenho, fidedignidade e transparência no recebimento, na aplicação e na prestação de contas de todos os recursos direcionados às escolas públicas do país.

\section{TECENDO CONSIDERAÇÕES}

O estudo da gestão orçamentária e financeira dessa escola da rede estadual de ensino de Pernambuco, tomada como foco neste trabalho, demonstrou o processo de análise e planejamento das etapas para a aplicação dos recursos direcionados a educação, de acordo com o que estabelece a Constituição Federal de 1988(BRASIL, 1988), identificando as leis e as exigências legais que respaldam esse direcionamento.

Os financiamentos oriundos, tanto da esfera Federal - PDDE, quanto do âmbito Estadual, direcionados à educação, têm sido de grande importância para fortalecer a autonomia do gestor, no desenvolvimento de uma real gestão democrática, e como mantenedores e provedores dos recursos humanos e materiais para respaldar essa gestão. No entanto, entraves como as irregularidades no envio desses recursos, o parco valor do montante (pré-

\footnotetext{
${ }^{33}$ SEE - Secretaria de Educação do Estado.
} 
estabelecido), enviado às escolas e a designação para o uso dos recursos enviados, além de desestabilizar o bom andamento das atividades desenvolvidas na, para e pela escola, deixa margem para possíveis falhas no que concerne a emissão de notas fiscais, a má aplicação dos recursos e a um direcionamento já estipulado para a aplicação do recurso em detrimento de outras possibilidades de uso.

Analisando-se essas ponderações, fica evidente que para a aplicação correta de todo e qualquer recurso financeiro destinado à educação é necessária a participação da sociedade, bem como o desenvolvimento de uma gestão democrática, comprometida com a transparência, com a ética e gerida por pessoas, cujo preparo permitam-Ihes enfrentar os desafios decorrentes dos apoucados recursos destinados à educação, implementando formas eficientes para o bom e fidedigno desenvolvimento de uma gestão orçamentária e financeira da escola pública brasileira.

\section{REFERÊNCIAS}

ANDRADE, N.A. Contabilidade Pública na Gestão Municipal. 1. ed. São Paulo: Atlas, 2002. Disponível no site: http://www.jurisway.org.br/v2/dhall.asp?id $\mathrm{dh}=5490$

Contabilidade Pública na Gestão Municipal. 4. Ed. São Paulo: Atlas, 2012.

AVILA, C.A. Gestão orçamentária e financeira. Curitiba: Instituto Federal do Paraná, 2011.

AVILA, C.A.; BÄCHTOLD, C.; VIEIRA, S.J. Noções de Contabilidade Pública. Sistema EscolaTécnica Aberta do Brasil - e-Tec Brasil. Curitiba: IFPR, 2011.

BÄCHTOLD. C. Contabilidade Pública. Curitiba: Instituto Federal do Paraná, 2009.

Responsabilidade Fiscal, Orçamento e Auditoria. Curitiba: Ibpex, 2003. 
(20)

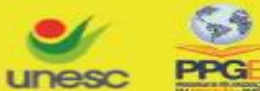

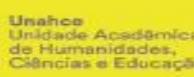
ediunesc

BRASIL. Constituição da República Federativa do Brasil, de 1988. Acesso aos 22/07/1012.

Disponível

em:

http://www.dji.com.br/constituicao federal/Constituição Federal165a169.htm

Artigo 165, da CONSTITUIÇÃO FEDERAL/88. Trata da criação das leis do Plano Plurianual, Lei das Diretrizes Orçamentárias e Lei orçamentária anual.

Disponível

no

site:

http://www.dji.com.br/constituicao federal/Constituição Federal165a169.htm. Acesso aos 22/07/2012.

Artigo 69, § 6, da Lei de Diretrizes Básicas. Prevê punição civil e criminal para o atraso da liberação dos recursos destinados à Educação. Disponível

em:

http://www.planalto.gov.br/ccivil 03/constituicao/constitui\%C3\%A7ao.htm

Emenda Constitucional n ${ }^{\circ}$ 14/96. Altera alguns dispositivos do art. 208 da Constituição Federal. Site acessado aos 22/07/2012. Disponível em: http://www.planalto.gov.br/ccivil 03/constituicao/constitui\%C3\%A7ao.htm

Lei $\mathbf{n}^{\circ}$ 4.320, de 17 de março de 1964. Institui Normas Gerais de Direito Financeiro para elaboração e controle dos orçamentos e balanços da União, dos Estados, dos Municípios e do Distrito Federal.

.Lei $\mathbf{n}^{\circ}$ 9.394, de 20 de dezembro de 1996(LDBEN). Estabelece as Diretrizes e Bases da Educação Nacional. Em seu Artigo 68 dispõe sobre os recursos financeiros destinados á educação. Acesso aos 15/07/2012. Disponível no

site: :http://portal.mec.gov.br/seed/arquivos/pdf/tvescola/leis/lein9394.pdf

. Lei n 9. 424, de 24 de dezembro de 1996. Dispõe sobre o Fundo de Manutenção e Desenvolvimento do Ensino Fundamental e de Valorização do Magistério.

Medida Provisória $n^{\circ}$ 1.784/98. Dispõe sobre o repasse de recursos financeiros do Programa Nacional de Alimentação Escolar, institui o Programa Dinheiro Direto na Escola, e dá outras providências. Disponível no site acessado aos 15/07/2012.

http://www.planalto.gov.br/ccivil 03/mpv/Antigas/1784.htm. 
Ministério do Planejamento, Orçamento e Gestão.Secretaria de

Orçamento Federal. Escola Virtual SOF.Curso Orçamento Público. Organização de FernandoCesar Rocha Machado. Brasília, 2014.

.Ministério do Planejamento, Desenvolvimento e Gestão. Secretaria de

Orçamento Federal. Manual técnico de orçamento MTO. Edição 2017. Brasília, 2016

CARVALHO, D. Orçamento e Contabilidade Pública: Teoria, Prática e mais de 800 exercícios. 5a Ed. Rio de Janeiro: Elsevier, 2010.

CORONEL. F. R. O processo de gestão em uma rede estadual pública: o ProgramaDinheiro Direto na Escola. Gestão em Rede. Consed. Brasília, jun. 2007. no 78, p.12.

CURY, C.R. O direito à educação: Um campo de atuação do gestor educacional na escola. Brasília: Escola de gestores, 2005.

DELPHINO, F.B.B. A Educação profissional: contraponto entre as políticas educacionais e o contexto do mundo produtivo. 1. Ed. São Paulo: Ícone, 2010. DOURADO, L.F. BRASIL. Ministério da Educação. Secretaria de Educação Básica. Programa Nacional de Fortalecimento dos conselhos escolares. Conselho Escolar e o Financiamento da Educação no Brasil. Brasília, 2006. GIACOMONI. J. Orçamento Público. 15ª Ed. São Paulo: Atlas, 2010.

GONTIJO, V. Princípios Orçamentários. Disponível em: http://www2.camara.leg.br/atividade-

legislativa/orcamentobrasil/cidadao/entenda/cursopo/principios.html>. Acesso em: 10 Abr. 2017.

KOHAMA, H. Contabilidade Pública: Teoria e Prática. $2^{\underline{a}}$ ed. São Paulo: Atlas, 1998.

OLIVEIRA, R.P.; ADRIÃO, T. Gestão, Financiamento e Direito à Educação: Analise da LDB e da Constituição Federal - São Paulo: Xamã, 2001.

. Gestão, Financiamento e Direito à Educação: Analise da LDB e da Constituição Federal - São Paulo: Xamã, 2. ed. 2002.

PALUDO, A.V. Orçamento Público, administração financeira e orçamentária e LRF. São Paulo: Método, 5. ed. 2015. 


\section{PLANK, D.N. Política Educacional no Brasil: Caminhos para a salvação} pública - Porto Alegre: Artmed Editora, 2001. 